\title{
Corrigendum
}

\section{Corrigendum to "Automatic Classification of Hypertension Types Based on Personal Features by Machine Learning Algorithms"}

\author{
Majid Nour $\mathbb{D}^{1}$ and Kemal Polat $\mathbb{D}^{2}$ \\ ${ }^{1}$ Department of Electrical and Computer Engineering, Faculty of Engineering, King Abdulaziz University, Jeddah 21589, \\ Saudi Arabia \\ ${ }^{2}$ Department of Electrical and Electronics Engineering, Faculty of Engineering, Bolu Abant Izzet Baysal University, \\ Bolu 14280, Turkey \\ Correspondence should be addressed to Kemal Polat; kpolat@ibu.edu.tr
}

Received 26 October 2020; Accepted 26 October 2020; Published 9 November 2020

Copyright (C) 2020 Majid Nour and Kemal Polat. This is an open access article distributed under the Creative Commons Attribution License, which permits unrestricted use, distribution, and reproduction in any medium, provided the original work is properly cited.

In the article titled "Automatic Classification of Hypertension Types Based on Personal Features by Machine Learning Algorithms" [1], there was an error in the reference provided for the PPG-BP database, which can be correctly accessed at [2].

\section{References}

[1] M. Nour and K. Polat, "Automatic classification of hypertension types based on personal features by machine learning algorithms," Mathematical Problems in Engineering, vol. 2020, Article ID 2742781, 13 pages, 2020.

[2] Y. Liang, Z. Chen, G. Liu, and M. Elgendi, "A new, shortrecorded photoplethysmogram dataset for blood pressure monitoring in China," Scientific Data, vol. 5, no. 1, Article ID 180020, 2018. 